\title{
The Correlation of Radiological Findings of Parotid Gland with Xerostomia Grade after Radiotherapy of Head and Neck Cancers
}

\author{
Radyoterapi Alan Baş-Boyun Kanseri Tanılı Hastalarda Kserostomi \\ Grade’i ile Parotis Bezi Radyolojik Bulguları Arasındaki Korelasyon
}

\author{
Neslihan Atabek $^{1}$, Fevziye İlknur Kayalı ${ }^{2}$, Zümrüt Arda Kayman Çerkeşli ${ }^{3}$, Uğur Toprak ${ }^{4}$ \\ ${ }^{1}$ Antalya Eğitim ve Araştırma Hastanesi, Radyasyon Onkolojisi Kliniği, Antalya, Türkiye \\ ${ }^{2}$ Ankara Numune Eğitim ve Araştırma Hastanesi, Radyasyon Onkolojisi Kliniği, Ankara, Türkiye \\ ${ }^{3}$ Süleyman Demirel Üniversitesi Hastanesi, Radyasyon Onkolojisi Anabilim Dalı, Isparta, Türkiye \\ ${ }^{4}$ Eskişehir Osmangazi Üniversitesi Tıp Fakültesi, Radyoloji Kliniği, Eskişehir, Türkiye
}

\begin{abstract}
ÖZET
GÍRIŞ ve AMAÇ: Baş-boyun kanserlerinin küratif definitif veya adjuvant radyoterapisi (RT) sonrasında en sık karşılaşılan kronik toksisite kserostomidir. Bu çalışmanın amacı baş-boyun kanserlerinin tedavisi için uygulanan RT sonrasında ortaya çıkan parotis bezindeki boyutsal ve parankimal değişiklikler ile klinik kserostomi derecesi arasındaki ilişkilerin incelenmesidir.

YÖNTEM ve GEREÇLER: Baş-boyun bölgesine 50-70 Gy küratif RT uygulanmış 50 hastanın 43'ü larinks (\%86), 3'ü nazofarenks (\%6) ve 4'ü oral kavite (\%8) kanseri tanılıdır. RT öncesi, RT sonrası ve tedavi sonrası 3. ay kontrollerinde çekilen bilgisayarlı tomografi veya manyetik rezonans görüntüleme yöntemlerinden parotis bezi boyutları ölçüldü ve parotis bezi parankimi, parotit açısından değerlendirildi. Takiplerde kserostomi derecelendirilmesi Radiation Therapy Oncology Group common toxicity criteria version 2.0'a göre yapıldı. Parotis bezi boyutları, parankimal parotit, evre, cerrahi, total RT dozu, fraksiyon dozu ve eş zamanlı kemoterapinin (KT) kserostomi derecesi ile ilişkisi değerlendirildi.

BULGULAR: Yirmi bir (\%42) hastada grade 1, 29 (\%58) hastada grade 2 kserostomi saptandi. Grade 1 ve grade 2 kserostomi grupları karşılaştırıldığında; grade 2 grubundaki hastaların daha ileri evre, daha az cerrahi yapılmış, daha çok eş zamanlı KT uygulanmış ve parotis boyutları daha fazla oranda küçülmüş olduğu görüldü ( $\mathrm{p}<0,01)$. Spearman $\rho$ analizleri sonucunda kserostomi derecesi ile evre ve eş zamanlı KT varlığının pozitif korelasyonu $(\mathrm{p}<0,001)$; fraksiyon dozu ve parotis boyutlarıyla negatif korelasyon $(\mathrm{p}<0,001)$ saptanırken; radyolojik parotitis varlığı ile anlamlı korelasyon bulunamadı $(\mathrm{p}>0.05)$.
\end{abstract}

TARTIŞMA ve SONUÇ: RT sonrası parotis bezi boyutlarının radyolojik olarak küçülmesi kserostomi derecesi ile korele iken radyolojik parotitis durumunun klinik kserostomi derecesini yansıtmayabileceği gösterilmiştir.

Anahtar Kelimeler: Baş-boyun kanseri, Radyoterapi, Kserostomi, Parotis bezi, Parotit

\begin{abstract}
INTRODUCTION: The most common chronic toxicity observed in head and neck cancer after curative definitive and adjuvant radiotherapy (RT) is xerostomia. The purpose of this study is to investigate the relationships between clinical xerostomia grade and the magnitude and parenchymal changes in the parotid gland ensuing after RT that is conducted for treating head and neck cancers.

METHODS: Fifty patients with larynx (43, 86\%), nasopharynx (3, 6\%), and oral cavity tumor $(4,8 \%)$, who were treated with 50-70 Gy curative RT in their head and neck regions, participated in the study. Patients were scanned by computerized tomography or magnetic resonance imaging before and after RT, as well as during the thirdmonth examinations after their treatments. Parotid gland sizes were measured and parotid gland parenchyma were assessed with regards to parotitis by analyzing the images. Xerostomia grading was carried out in accordance with the common toxicity criteria version 2.0 of the Radiation Therapy Oncology Group. Relationships of xerostomia grade with parotid gland size, parenchymal parotitis, stage, operation, total RT dosage, fraction dosage, and concurrent chemotherapy were analyzed.
\end{abstract}


RESULTS: Twenty-one (42\%) patients had grade 1 xerostomia and $29(58 \%)$ patients had grade 2 xerostomia. Compared to Grade 1 xerostomia group; Grade 2 patients were more advanced stage, had less surgery but more concurrent chemotherapy, and had further reduced parotid sizes $(\mathrm{p}<0.01)$. Spearman $\rho$ analyses revealed that xerostomia grade had significant positive correlations with stage and presence of concurrent chemotherapy $(\mathrm{p}<0.001)$; significant negative correlations with fraction dosage and parotid sizes $(\mathrm{p}<0.001)$. However, xerostomia grade did not significantly correlate with presence of radiological parotitis $(\mathrm{p}>0.05)$.

DISCUSSION AND CONCLUSION: Reduction in the parotid gland sizes after RT treatment is correlated with xerostomia grade. However, radiological parotitis condition may not indicate the grade of clinical xerostomia.

Keywords: Head-neck cancer, Radiotherapy, Xerostomia, Parotid gland, Parotitis

\section{GíRIŞ}

Baş-boyun kanserleri en sık oral kavite, larinks, farinks ve hipofarinksten kaynaklanır. Nazal kavite ve paranazal sinüs kanserleri, tükrük bezi maligniteleri, çeşitli sarkomlar, lenfoma ve malign melanom daha nadir görülür (1). Başboyun tümörleri tüm kanserlerin \%4'ü olmasina ve vücudun küçük bir bölümünde yer almasına rağmen, fizyolojik fonksiyonlar, görünüş, ifade ve sosyal ilişkiler açısından kritik öneme sahip bir bölgede yerleşirler. $\mathrm{Bu}$ nedenledir ki hastanın yaşam kalitesini en az etkileyecek şekilde tedavi; baş-boyun cerrahları, rekonstrüktif cerrahlar, radyasyon onkologları, medikal onkologlar, patologlar, radyologlar, psikiyatristler ve diğer konu ile ilgili sağlık personellerini içeren multidisipliner bir ekiple en uygun şekilde belirlenmelidir (2).

Tek başına radyoterapi uygulanması özellikle erken evre larinks tümörlerinde cerrahi kadar etkilidir. Radyoterapi lokal ileri evre tümörlerde cerrahi sonrası kemoterapi ile kombine olarak kullanılırken, operabl olmayan tümörlerin tedavisinde preoperatif olarak kemoterapi ile kombine kullanılip yanit değerlendirilmesi sonrası uygun hastalarda cerrahiye olanak sağlamaktadır. Çok ileri evre ve metastatik vakalarda ise kitleyi küçültmek, kritik organlara bası etkisini ortadan kaldırmak ve ağrıy azaltmak için, palyatif amaçla uygulanabilmektedir (3). Baş-boyun bölgesine uygulan RT ile çeşitli erken ve geç yan etkiler ortaya çıkar. Normal dokularda erken etkiler tedavi sonrası ilk günlerde ya da haftalarda ortaya çıkarken; geç yan etkiler, RT'den aylar, yıllar ya da dekadlar sonra ortaya çıkabilir. Mukozit, yaş ya da kuru deskuamasyon, epilasyon, tükrük azalması erken yan etkiler iken; fibrozis, deri atrofisi, hipotiroidi, tükrük bezi fonksiyon kaybı, beyin nekrozu, duyma kayb1, sekonder kanser gelişimi, özofagus striktürü, katarakt, retinopati, diş kaybı, mandibula ve maxilla osteoradyonekrozu ve radyasyon myeliti geç yan etkilerdir (4).

Kliniğimizde baş-boyun tümörlü hastalar tüm hastalarımızın \%7-11'ini oluşturmaktadır. RT uygulanan bu hastalarda en s1k görülen yan etkilerden biri de parotis bezi fonksiyon bozukluğuna bağlı ağız kuruluğu (kserostomi) olup, uygulanan RT dozlarına ve RT alanı içinde kalan parotis bezi volümüne bağlı olarak değişmektedir. $\mathrm{Bu}$ sorun beraberinde konuşma ve tat duyusu değişiklikleri, yemek yiyememe, kilo kaybını getirmekte olup, hastanın konforunu büyük oranda bozmakta ve kalıcı olabilmektedir. Kserostomi derecelendirilmesi klinik olarak hastaların subjektif bildirimlerine göre yapılmaktadır. Parotis bezinin RT sonras 1 boyutsal ve parankimal değişikliklerinin klinik kserostomi şiddetini öngörmedeki değerini araştırmak amacıyla bu çalışmada hastaların RT öncesi, sonrası ve 3 . ay kontrollerindeki parotis bezi boyutları ve parankim değişikliklerinin kserostomi ile ilişkisi incelendi. Ayrıca kserostomi üzerine etkili olabilecek evre, tedavi dozu, eş zamanlı KT ve cerrahi gibi faktörler değerlendirildi.

\section{GEREÇ VE YÖNTEM}

\section{Çalışma Grubu}

Ocak 2009-Ocak 2011 yılları arasında tek merkez Radyasyon Onkolojisi kliniğinde küratif definitif veya cerrahi sonrası adjuvan RT (eksternal konformal radyoterapi) uygulanan, histopatolojik olarak larinks, nazofarinks veya oral kavite kanseri tanısı almış olan 50 hasta çalışmaya dahil edildi. Eastern Cooperative Oncology Group (ECOG) performans durumu 0-2, 18 yaş üstü, The AJCC Cancer Staging Manual'e göre T1-4, N0-3 ve M0 olarak evrelenen, uygulanan RT dozu 50-70Gy olup bilateral parotis bezleri RT'ye maruz kalan hastalar çalışmaya dahil edildi. Performans 
durumu kötü olan (ECOG 3-4), 18 yaș altı, uzak metastazı olan, herhangi bir sebepten dolayı RT'yi tamamlayamamış veya daha önce aynı bölgeye RT almış olan hastalar çalışma dış1 birakıldı.

$\mathrm{Bu}$ çalışma Ankara Numune Eğitim ve Araştırma Hastanesi Bilimsel Araştırmalar Değerlendirme Komisyonu tarafindan değerlendirilip onaylanmıştır (protokol no: 2011-135 23/03/2011). Araştırma, Dünya Tabipler Birliğinin Helsinki Bildirgesine uygun olarak yürütülmüştür.

\section{Radyoterapi}

Hastaların RT simülasyonu supin pozisyonda, kollar gövdenin her iki yanında olacak şekilde, termoplastik baş-boyun maskesi kullanılarak baş sabitlemesi yapılarak uygulandı. Oral kavite tümörlü hastalarda dil basacağı (mouth bite) kullanılarak sert damak alan dışında birakıldı. Hedef volüm belirlenmesi International Commitee of Radiation Units and Measurements 50 (ICRU50) raporları göz önüne alınarak yapıldı. Tedavi alanları karşılıklı iki paralel alan üzerinde kişiye özel koruma blokları ile tasarlandı. RT; lokal ileri evre larinks ca ve dil ca tanılı hastalara günde $1 \mathrm{kez}$, haftada 5 gün, 1.8-2 Gy fraksiyon dozu ile düşük riskli bölgelere toplam $50 \mathrm{~Gy}$, yüksek riskli bölgelere toplam 60-70 Gy olarak planland 1 ve uygulandi. Erken evre larinks kanseri tanılı hastalara $2.25 \mathrm{~Gy} /$ fraksiyon dozu ile $63 \mathrm{~Gy}$, nazofarinks kanseri tanılı hastalara 2 Gy/fraksiyon dozu ile toplam 70 Gy RT uygulandi. Endikasyonu olan hastalarda RT ile eş zamanlı haftalık sisplatin bazlı KT 25$35 \mathrm{mg} / \mathrm{m}^{2} /$ gün dozunda haftada bir uyguland.

\section{Klinik ve Radyolojik Değerlendirme}

Tüm hastaların RT öncesi, RT bitiminde ve sonrasında ilk kontrollerinde (3. ayda) çekilen baş-boyun bölgesi bilgisayarlı tomografileri ve/veya manyetik rezonans görüntülemeleri ayn1 uzman radyolog tarafindan değerlendirilmiş olup, hastaların parotis bezi derin lob, yüzeyel lob ve toplam parotis bezi boyutları aksiyel kesitlerde ölçüldü, ayrıca tedavi ile ilişkili parotitis varlığı/yokluğu değerlendirildi. Hastaların RT öncesi, sonrası ve kontrollerindeki kserostomi semptomları Radiation Therapy Oncology Group (RTOG) akut radyasyon morbidite skorlama kriterleri kullanılarak derecelendirildi (5) (Tablo 1).
Hastalara uygulanan total RT dozu, fraksiyon dozu, RT ile eş zamanlı KT uygulanma durumu, parotis bezinin tedavi öncesi sonrası ve 3 aydaki kontrol boyutları ile radyolojik olarak parotitis varlığının klinik kserotomi derecesi ile korelasyonu incelendi.

\section{Istatistiksel Analiz}

Tüm istatistiksel analizler Statistical Package for the Social Sciences software program version 21.0 (SPSS Inc., Chicago, IL, USA) ile yapıld1. Hastaların RT öncesi ve sonrası parotis bezi boyutları Friedman Testi ile karşılaştırıldı. Grade 1 ve 2 kserostomi görülen hasta gruplarının özellikleri arasındaki fark MannWhitney U test veya Chi-Square testi ile değerlendirildi. Sağ ve sol parotis bezlerinin RT öncesi, sonrasi ve 3. ay kontroldeki boyutsal değişimlerinin kserostomi grade 1 ve 2 hasta grupları arasındaki farkı ise Kruskal-Wallis testi ile değerlendirildi.p $<0,05$ istatistiksel olarak anlamlı kabul edilmiştir.

Tablo 1. RTOG akut radyasyon morbidite skorlama kriterleri (5)

\begin{tabular}{ll}
\hline Grade & Tanım \\
\hline 0 & $\begin{array}{l}\text { Bazal tükürük salgısında değişiklik yok. } \\
\text { Hafif ağız kuruluğu/ hafifçe koyulaşmış } \\
\text { tükürük kivamı/ hafif tat değişikliği } \\
\text { (metalik tat)/ bu değişikliklerle } \\
\text { yemeklerde sıvı alımı artarken, bazal } \\
\text { beslenme alışkanlıklarında değişiklik } \\
\text { yoktur. }\end{array}$ \\
2 & $\begin{array}{l}\text { Orta derece veya tam ağız kuruluğu/ } \\
\text { yapışkan, kıvamı koyulaşmış tükürük. }\end{array}$ \\
3 & ------- \\
4 & Akut tükürük bezi nekrozu \\
\hline
\end{tabular}

\section{BULGULAR}

Çalışmaya dahil edilen 50 hastanın medyan yaşı 54 (34-78) olup, hastaların 3'ü (\%6) kadın, 47'si (\%94) erkektir. Primer kanser bölgesi olarak hastaların 43'ü (\%86) larinks, 3'ü (\%6) nazofarenks ve 4'ü (\%8) oral kavite kanseri tanılıdır. Primer tümörün yerleşim yerine göre hastaların dağılımı Tablo 2'de gösterilmiştir.

Hastaların \%60'1 (30 hasta) opere olmamıştır, yalnızca histopatolojik tanı için doku örneklemesi yapılmıştır. Bu hastaların 
3'ünde operasyon önerilmesine karşın hastalar kabul etmemiş, bir hasta da medikal nedenlerle opere olamamıştır. Opere olan 13 hastaya (\%26) total larenjektomi + boyun lenf nodu diseksiyonu (BLND), 3 hastaya (\%6) supraglottik larenjektomi + BLND uygulanmıştır. Retromolar trigon yerleşimli oral kavite tümörlü 1 hastaya (\%2) tümör eksizyonu yapılmış, 1 hastaya $(\% 2)$ parsiyel larenjektomi + BLND uygulanmış, dil yerleşimli oral kavite tümörlü 1 hastaya $(\% 2)$ sol hemiglossektomi + BLND uygulanmış ve 1 hastaya $(\% 2)$ da kordektomi yapılmıştır. Opere olan hastaların patolojik evrelemesi, opere olmayan hastaların ise klinik evrelemesi yapıldığında 9 hasta (\%18) Evre I, 15 hasta (\%30) Evre II, 12 hasta (\%24) evre III ve 14 hasta $(\% 28)$ evre IVA olarak değerlendirildi.

Tablo 2. Tanı ve yerleşim yeri

\begin{tabular}{lll}
\hline Tanı & Yerleşim Yeri & $\mathbf{n}(\%)$ \\
\hline Larinks kanseri & Glottik & $25(50)$ \\
& Supraglottik & $18(36)$ \\
$\begin{array}{l}\text { Nazofarinks } \\
\text { kanseri }\end{array}$ & Nazofarinks & $3(6)$ \\
$\begin{array}{l}\text { Oral kavite } \\
\text { tümörü }\end{array}$ & $\begin{array}{l}\text { Retromolar damak } \\
\text { trigon }\end{array}$ & $1(2)$ \\
& Dil & $2(2)$ \\
\hline
\end{tabular}

Not: "n" hasta sayısını temsil etmektedir.

Opere olmamış 30 hastanın (\%60); 3'ü (\%6) nazofarinks, 2'si (\%4) oral kavite, 25'i (\%50) larinks kanseri tanılı olup küratif definitif radyoterapi uyguland1. Larinks kanseri tan 1118 hastaya (\%36) operasyon sonras1 küratif adjuvan RT, 2 oral kavite tümörlü hastaya (\%4) küratif adjuvan RT uygulandı.

Tüm hastalara planlanmış hedef hacme (planned target volüme-PTV) yüksek risk volümüne total doz median $64 \mathrm{~Gy}$ (60Gy-70Gy) olarak ve 1 hastaya $1.8 \mathrm{~Gy}, 32$ hastaya 2 Gy ve 17 hastaya 2.25 Gy fraksiyon dozu ile tedavi uygulandı. Hastaların \%44'üne (22 hasta) RT ile eş zamanlı KT uygulanırken hastaların \%56'sına (28 hasta) eș zamanlı KT uygulanmamıştır. Parotis bezi boyutları RT öncesi, sonrası ve ilk kontrollerinde çekilen bilgisayarlı tomografi ve/veya manyetik rezonans görüntülemelerinden aynı uzman radyolog tarafindan milimetre cinsinden bezin 3 boyutu ölçülerek $\mathrm{mm}^{3}$ şeklinde hesaplanmış, parotis bezleri sağ, sol, derin, yüzeyel ve toplam boyutları değerlendirilmiştir. Tüm hastaların RT öncesi, RT sonrası ve ilk kontrollerinde ölçülen parotis bezi boyutları median değerleri sırasıyla sağ parotis bezi için $30,5 \mathrm{~mm}^{3}, 29 \mathrm{~mm}^{3}$ ve $29 \mathrm{~mm}^{3}$; sol parotis bezi için $32 \mathrm{~mm}^{3}, 30 \mathrm{~mm}^{3}$ ve $29 \mathrm{~mm}^{3}$ idi. Friedman testi sonucunda hem sağ $(p<0,001)$ hem sol $(p<0,001)$ parotis bezi boyutlarının değişiminin istatistiksel olarak anlamlı farklı olduğu görülmüştür.

Takiplerde $21(42 \%)$ hastada klinik olarak grade 1, 29 (58\%) hastada grade 2 kserostomi saptand. Kserostomi gelişmeyen (grade 0) veya grade 4 kserostomi gelişen hasta olmad1. Kserostomi grade 1 ve 2 olan hasta gruplarının özellikleri karşıllaştırıldığında yaş, primer kanser bölgesi, total PTV high-risk dozu ve radyolojik parotitis varlığ 1 açısından herhangi bir fark görülmedi (surasiyla $\mathrm{p}=0.431$, $\mathrm{p}=0.906, p=0.475$ ve $\mathrm{p}=0.205$ ) (Tablo 3). Grad 1 kserostomi grubunda T1-2 evreler çoğunlukta iken grad 2 kserostomi grubunda T3-4 evreler çoğunlukta idi $(p<0,001)$. Benzer şekilde grad 2 kserostomi grubunda nod pozitif 11 hasta var iken grad 1 kserostomi grubunun tamamı nod negatif hastalardan oluşmaktadır $(\mathrm{p}=0,006)$. Grad 1 kserostomi grubundaki hastalar daha çok cerrahi sonrasi adjuvan RT uygulanan hastalar olduğu görülmüştür $(\mathrm{p}=0,002)$. Ayrıca grad 2 kserostomi grubundaki hastaların eş zamanlı KT uygulanma oranı \%69 iken grad 1 kserostomi grubunda eş zamanlı KT \%9,5 hastaya uygulanmıştır $(p<0,001)$. Sağ ve sol parotis bezi boyutlarının RT sonrasi median değerlerine bakıldığında Grad 2 kserostomi grubunda istatistiksel olarak anlamlı küçük olduğu saptanmıştır $(\mathrm{p}<0,001)$.

Kserostomi şiddeti üzerinde etkili olabilecek olası faktörleri tespit etmek amacıyla kserostomi derecesi ile yaş, cerrahi, total RT dozu, fraksiyon dozu, eş zamanlı KT, T evresi, $\mathrm{N}$ evresi, RT öncesi sonrası ve ilk kontroldeki parotis bezi radyolojik boyutları ve radyolojik parotitis ilişkisi Spearman korelasyon testi ile incelendi. T evresi, $\mathrm{N}$ evresi, eş zamanlı KT ve cerrahi yapılmış olması ile kserostomi derecesi arasında pozitif korelasyon saptanırken fraksiyon dozu ile negatif korelasyon görüldü $(\mathrm{p} \leq 0,001)$. RT öncesi parotis bezi boyutları ile kserostomi arasında ise anlamlı bir korelasyon 
bulunmad. RT bittikten sonraki ve 3. ay kontrolde parotis bezi boyutlarınındaki küçülme ne kadar fazla ise kserostomi şiddetinin artı̆̆ 1 gösterildi $(\mathrm{p} \leq 0,001)$. Buna karşın radyolojik olarak parotitis varlığının ise kserostomi derecesi ile anlamlı bir korelasyonu saptanmad $_{1}(\mathrm{p}=0,270)$ (Tablo 4).

Tablo 3. Kserostomi Grade 1 ve 2 grupları ile tüm hastaların genel karakteristikleri

\begin{tabular}{|c|c|c|c|c|}
\hline Karakteristikler & Tüm Hastalar & Grade 1 & Grade 2 & $\mathbf{p}$ \\
\hline$\overline{\mathrm{n}}$ & 50 & 21 & 29 & \\
\hline \multicolumn{5}{|l|}{ Yaş } \\
\hline Medyan (En düşük-En yüksek) & $54(38-78)$ & $55(44-74)$ & $53(38-78)$ & 0,431 \\
\hline \multicolumn{5}{|l|}{ Tanı } \\
\hline Larinks kanseri & $43(86 \%)$ & $18(85,7 \%)$ & $25(86,2 \%)$ & \multirow[t]{3}{*}{0,906} \\
\hline Nazofarinks kanseri & $3(6 \%)$ & $1(4,8 \%)$ & $2(6,9 \%)$ & \\
\hline Oral kavite tümörü & $4(8 \%)$ & $2(9,5 \%)$ & $2(6,9 \%)$ & \\
\hline \multicolumn{5}{|l|}{ T Evresi } \\
\hline 1 & $9(18 \%)$ & $9(42,8 \%)$ & 0 & \multirow[t]{4}{*}{$<0,001$} \\
\hline 2 & $17(34 \%)$ & $11(52,4 \%)$ & $6(20,7 \%)$ & \\
\hline 3 & $15(30 \%)$ & 0 & $15(51,7 \%)$ & \\
\hline 4 & $9(18 \%)$ & $1(4,8 \%)$ & $8(27,6 \%)$ & \\
\hline \multicolumn{5}{|l|}{ N Evresi } \\
\hline 0 & $39(78 \%)$ & $21(100 \%)$ & $18(62,1 \%)$ & \multirow[t]{3}{*}{$<0,01$} \\
\hline 1 & $3(6 \%)$ & 0 & $3(10,3 \%)$ & \\
\hline 2 & $8(16 \%)$ & 0 & $8(27,6 \%)$ & \\
\hline \multicolumn{5}{|l|}{ Cerrahi } \\
\hline Evet & $20(40 \%)$ & $3(14,3 \%)$ & $17(58,6 \%)$ & \multirow[t]{2}{*}{$<0,01$} \\
\hline Hayır & $30(60 \%)$ & $18(85,7 \%)$ & $12(41,4 \%)$ & \\
\hline $\begin{array}{l}\text { Total PTV yüksek risk doz } \\
\text { Medyan (En düşük-En yüksek) }\end{array}$ & 64Gy(50-70Gy) & 63 Gy (50-70 Gy) & 66 Gy (56-70Gy) & 0,475 \\
\hline \multicolumn{5}{|l|}{ Fraksiuon dozu } \\
\hline 1,8 Gy & $1(2 \%)$ & 0 & $1(2 \%)$ & \multirow[t]{3}{*}{$<0,001$} \\
\hline 2,0 Gy & $32(64 \%)$ & $4(19 \%)$ & $28(98 \%)$ & \\
\hline $2,25 \mathrm{~Gy}$ & $17(34 \%)$ & $17(81 \%)$ & 0 & \\
\hline \multicolumn{5}{|l|}{ Konkürren KT } \\
\hline Evet & $22(44 \%)$ & $2(9,5 \%)$ & $20(69 \%)$ & \multirow[t]{2}{*}{$<0,001$} \\
\hline Hayır & $28(56 \%)$ & $19(90,5 \%)$ & $9(31 \%)$ & \\
\hline \multicolumn{5}{|l|}{$\begin{array}{l}\text { Total Sağ parotis bezi boyutu }\left(\mathrm{mm}^{3}\right) \\
\text { Medyan (En düşük-En yüksek) }\end{array}$} \\
\hline RT Öncesi & $30,5(18-50)$ & $38(22-50)$ & $30(18-45)$ & \multirow[t]{3}{*}{$<0,001$} \\
\hline RT Sonrası & $29(11-45)$ & $35(21-45)$ & $25(11-40)$ & \\
\hline 3. ay kontrol & $29(15-48)$ & $35(24-48)$ & $25(15-40)$ & \\
\hline \multicolumn{5}{|l|}{$\begin{array}{l}\text { Total sol parotis bezi boyutu }\left(\mathrm{mm}^{3}\right) \\
\text { Medyan (En düşük-En yüksek) }\end{array}$} \\
\hline RT Öncesi & $32(18-45)$ & $33(21-45)$ & $30(18-45)$ & $<0,001$ \\
\hline
\end{tabular}




\begin{tabular}{lcccc} 
RT Sonrasi & $30(15-45)$ & $35(18-45)$ & $23(15-40)$ & \\
3. ay kontrol & $29(15-48)$ & $35(25-48)$ & $25(15-35)$ & \\
Radyolojik Parotit & & & & \\
Evet & $33(66 \%)$ & $12(57,1 \%)$ & $21(72,4 \%)$ & 0,205 \\
Hayır & $17(34 \%)$ & $9(42,9 \%)$ & $8(27,6 \%)$ & \\
\hline
\end{tabular}

Tablo 4. Olası etkenler ile RT sonrası kserostomi arasındaki ilişkiler üzerinde yapılmış Spearman's $\rho$ analizlerinin sonuçları

\begin{tabular}{|c|c|c|}
\hline & $\rho$ & $\mathbf{p}$ \\
\hline Yaş & -0.112 & 0,437 \\
\hline T Evresi & 0.721 & $0,001 * * *$ \\
\hline N Evresi & 0.449 & $0,001 * * *$ \\
\hline Cerrahi & 0.447 & $0,001 * * *$ \\
\hline PTV yüksek risk total RT doz & 0.102 & 0,481 \\
\hline Fraksiyon RT doz & -0.835 & $0,001 * * *$ \\
\hline Konkürren KRT & 0.591 & $0,001 * * *$ \\
\hline RT Öncesi sağ parotis bezi radyolojik boyutu & -0.279 & 0,051 \\
\hline RT Öncesi sol parotis bezi radyolojik & -0.247 & 0,084 \\
\hline RT Sonrası sağ parotis bezi radyolojik & -0.503 & $0,001 * * *$ \\
\hline RT Sonrası sol parotis bezi radyolojik & -0.476 & $0,001 * * *$ \\
\hline 3. ay sağ parotis bezi radyolojik & -0.563 & $0,001 * * *$ \\
\hline 3. ay sol parotis bezi radyolojik & -0.625 & $0.001 * * *$ \\
\hline RT Sonrası radyolojik parotit & 0.159 & 0,270 \\
\hline
\end{tabular}

\section{TARTIŞMA}

Kserostomi konvansiyonel RT sonrası sik görülen yan etkilerden biridir.7,2Gy'den sonra tükrük akımı yarıya düşer, 36Gy'de en az seviyeye gelir (6). Tedaviden sonraki 2 yıl aynı şekilde sürer. $\mathrm{Bu}$ çalışmada hastaların RT öncesi kserostomi semptomu yokken (RTOG Grad 0), RT sonrasında hastaların tümü kserostomi semptomu tariflemekteydi. Rodrigues ve arkadaşlarının yaptığı çalışmada (7) baş-boyun bölgesine lenfoma nedeniyle RT alan 15 hastada tükrük bezi disfonksiyonunun (RTOG toksisite skalası ile değerlendirilmiş) yaşam kalitesine etkisi (EORTC Quality of Life Questionnaire - H\&N-35 anketi ile değerlendirilmiş) ile RT doz-cevap ilişkisi değerlendirilmiş. RT sırasında \%47 hastada Adress for correspondence: Radyasyon Onkolojisi Kliniği Antalya Eğitim ve Araștırma Hastanesi Vaatk e-mail: atabekneslihan@gmail.com

grad 2 kserostomi görülürken, bu hastaların 1/3'ünde semptomları 2 yıl süresince devam ettiği görülmüştür. En az bir parotis bezine ortalama $>31$ Gy RT alan hastalarda 6 . aydaki ağız kuruluğu \%17, yapışkan tükrük kıvamı \%25 görülürken, minör tükrük bezlerine ortalama $>11$ Gy RT alanlarda yapışkan tükrük kıvamı \%25 oranında görülmüştür. Sonuç olarak parotis bezi dozunu ortalama $\leq 31 \mathrm{~Gy}$ 'de, minör tükrük bezi dozunu ortalama $\leq 11 \mathrm{~Gy}$ 'de tutmanın subakut kserostomi riskini azalttığ gösterilmiş.

Hey ve arkadaşlarının yaptığı çalışmada (8); Baş-boyun tümörlü yalnız RT alan (61 hasta) veya cisplatin ile kemoradyoterapi (KRT) alanların (36 hasta) tükrük bezi fonksiyonları, tükrük bezi akım hızı tedavi sirasinda, 2 . ve 6 . haftalar ile tedavi 
sonrası 4. hafta ve 6 . ayda değerlendirilmiş. Klinik hedef hacim (CTV) 1'e (primer tümör ve tutulu LN bölgesi) 64-70 Gy RT uygulanmış. CTV2'ye (düşük risk bölgeleri) 50Gy RT uygulanmış. Normal doku komplikasyon olasılığ 1 Toksik doz (hastaların \%50'sinde toksisite oluşturan doz, TD) 50 değeri KRT alan kolda 4. hafta için 32,2 Gy, 6. ay için 32,1 Gy iken, RT alan kolda 4. hafta için 41,1 Gy, 6. ay için 39,6 Gy bulunmuş. TD50'nin tolere edilebilir dozu KRT kolunda, yalnız RT koluna göre 7-8 Gy daha az bulunmuş. Bu çalışma ile KRT'nin parotis bezinde daha yüksek oranda hasara sebep olduğu gösterilmiş. Yoğunluk ayarl1 radyoterapi (Intensity modulated radiotherapy - IMRT) kullanımının artması ile parotis bezi RT sensitivitesinin cisplatin ile artışının önüne geçilmesi beklenmektedir. Çalışmamızda Grade 2 kserostomi olan hasta grubunda grade 1 olan gruba göre daha fazla eşzamanlı KT olan hasta olduğu görülmüştür $(p<0,001)$. Ayrıca eş zamanlı KT ile kserostomi gradı arasında istatistiksel anlamlı korelasyon saptanmıştır $(\mathrm{p}<0,001)$.

Ricchetti ve arkadaşlarının yaptığ (9); Orofarinks ca tanıl1 26 hastada IMRT \pm KT sırasında risk altındaki seçilmiş organların volümetrik değişimi incelenmiş. Hastalara haftada bir bilgisayarlı tomografi yapılarak veriler elde edilmiş. Parotis bezi, submandibüler bez, larinks, sternokleidomastoid kas volümleri ölçülmüş. Tüm ölçümü yapılan organlarda 5 hafta sonras1 değişiklikler saptanmıştır. 7. Haftada yapılan ölçümde volüm değişikliği en fazla parotis bezinde olduğu görülmüștür. Tüm seçilmiş risk altındaki organlarda anlamlı istatistiksel değişiklikler kaydedilmiş.

Teshima ve arkadaşlarının yaptığ 1 çalışmada (10); İleri evre, 20 oral skuamöz hücreli karsinom tanılı hastaya preoperatif RT uyulanmış. Hastanın parotis bezi boyutları MRI veya $\mathrm{BT}$ ile değerlendirilmiş. 30Gy RT sonras1 parotis bezi volümü $68,2 \mathrm{~cm}^{3}$ 'den, $47,9 \mathrm{~cm}^{3}$ 'e düşmüş $(\mathrm{p}=0.01)$. RT öncesi ve sonrası parotis bezi volüm \%85'den \%54'e değişmektedir. Parotis volümü ile tükrük salgıs1 azalmas1 arasında korelasyon görülmüş.

Başka bir çalışmada Broggi ve arkadaşları (11); Baş-boyun bölgesine IMRT ile RT alan 174 hastada parotis bezi boyutlarındaki azalma RT öncesi ve sonrası çekilen bilgisayarlı tomografiler ile değerlendirilmiş. Boyutlarda $\% 26$ oranında azalma gösterilmiş $(\mathrm{p}<0.001)$. Çalışmamızda literatüre ek olarak parotis bezi boyutlarındaki küçülmenin kserostomi derecesi ile korelasyonu değerlendirildi ve istatistiksel anlamlı negatif korelasyon saptad $1(p<0,001)$. Ayrıca Grade 2 kserostomi görülen hasta grubunda grade 1 grubuna göre parotis boyutlarının daha fazla azaldığı tespit edildi $(p<0,001)$. Parotis bezi boyutlarındaki radyolojik küçülme ne kadar fazla ise kserostomi şiddetinin arttığı görüldü. Buna karşın radyolojik parotitis bulunması ile klinik kserostomi derecesi arasında istatistiksel olarak anlamlı bir ilişki tespit edilememiştir $(\mathrm{p}=0,270)$.

Deasy ve arkadaşlarının yaptığı çalışmada (12); Geç tükrük bezi disfonksiyonu ortalama parotis dozu ile ilişkili bulunmuştur. Ciddi kserostomi (tükrük bezi fonksiyonunu bazalin $<\% 25$ 'i ise) en az bir parotis dozu ortalama <20Gy doz verilerek korunursa veya her iki parotis bezine ortalama $<25 \mathrm{~Gy}$ doz verilirse, büyük oranda engellenebilir. Özellikle IMRT gibi tekniklerle parotis bezi daha iyi korunabilir. Parotis bezi ortalama dozu ne kadar düşük tutulursa, daha iyi fonksiyon sağlanır. Ayrica submandibüler bezin korunması da kserostomi riskini önemli ölçüde azaltır. Çalışmamızda kserostomi derecesi hasta bildirimine dayanan RTOG toksisite skalasında göre yapılmıştır. Tükrük bezi salgısının kantitatif değerlendirilmesinin yapılmamış olması bu çalışmanın başlıca kısıtllılığıdır.

Dijkema ve arkadaşlarının yaptığ çalışmada (13); Baş-boyun bölgesi malignitesi nedeniyle IMRT veya konvansiyonel RT ile tedavi edilen 222 hastanın, tedavi sonras1 1 . yılda parotis bezi fonksiyonu tükrük akım hızı ile değerlendirilmiş. Hastalara GTV'ye konvansiyonel RT ile 50-70 Gy (2Gy/frk), IMRT ile 2-2,3Gy/frk, toplam 69-70Gy, haftada 5 kez uygulanmış. 384 parotis bezi incelendiğinde ortalama parotis dozu TD50 değeri 39,9Gy olup, ortalama 25-30Gy dozların \%17-26 normal doku komplikasyon olasılığına sebep olduğu görülmüştür.

Yaptığımız çalışmada hastaların parotis bezleri bilgisayarlı tomografi ve/veya manyetik rezonans görüntüleme ile değerlendirilmiş. Parotis bezi boyut ve fonksiyonları aşağıdaki çalışmalarda belirtildiği gibi değişik yöntemlerle de değerlendirilebilmektedir. 
Dirix ve arkadaşlarının yaptığ 1 çalışmada (14); Difüzyon ağırlıklı MRI ile 8 baş boyun bölgesi tümörü olan ve parotis bezi koruyarak RT alan (karşı parotis ortalama dozu $<26 \mathrm{~Gy}$ ) hastalar değerlendirilmiş. Bu değerler tükrük bezi sintigrafisi ile karşılaştırılmış. Hastaların korunan parotis bezi ile diğer parotis arasında belirgin fark görülürken, sintigrafik değerler ile MRI değerleri uyumlu olarak bulunmuştur. $\mathrm{Bu}$ sonuçlar MR'in non-invaziv olması nedeniyle daha uygulanabilir olduğunu göstermiştir.

Marzi ve arkadaşlarının yaptığ çalışmada (15); Baş-boyun kanserli IMRT ile tedavi edilen 59 hastanın RTOG toksisite skoru ile kserostomi semptomu ve stimüle edilmiş ve edilmemiş tükrük akımları değerlendirilmiş. Ölçümler RT öncesi ve RT sonrası 3, 6, 12, 18 , 24. aylarda yapılmış. TD50 değerleri 3, 6, 12 aylarda $21.4,27.8$ ve 41.6 olarak bulunmuş. RT sonrası tükrük bezi fonksiyonundaki düzelme genellikle RT'den 1 y1l sonra görülmektedir.

\section{SONUÇ}

Baş-boyun malignitelerinde RT sonrası gelişen kserostominin klinik skorlamas1 hastaların subjektif bildirimlerine göre yapılmaktadır, tükrük bezi fonksiyonunun değerlendirilebilmesi için yapılacak ek tetkikler maliyeti arttırabilmektedir. Çalışmamızda hastaların primer kanserlerini değerlendirmek üzere çekilen kontrol BT/MRI görüntülerinden yapılacak parotis bezi boyut ölçümlerinin kserostomi derecesi ile korele olduğu görülmüştür. Parotis bezi boyutlarının küçülmesi kserostomi derecelendirmesi için objektif bir yöntem olarak kullanılabilir.

\section{REFERANSLAR}

1. Cardesa, Antonio; Slootweg, Pieter J.(Eds.) "patology of the head and neck" Springer, 2006, 180-2

2. K. Kian Ang, Head and neck tumors, Gunderson and Tepper, Clinical Radiation Oncology, 2007, 629
3. Myers EN, Suen JY. Cancer of head and neck. Churchill Livingstone Inc. Broadway New York, Edinburg, London, Melbourne, $2^{\text {nd }}$ Edition: $159-178,1989$

4. Travis EL. Organizational response of normal tissues to irradiation. Semin Radiat Oncol 2001;11:184-197.

5. Toxicity criteria of the Radiation Therapy Oncology Group (RTOG) and the European Organization for Research and Treatment of Cancer (EORTC)." Cox JD et al. Int J Radiat Oncol Biol Phys. 1995 Mar 30;31(5):1341 6.

6. Jen YM, Lin YC, Wang YB. Dramatic and prolonged decrease of whole salivary secretion in nasopharyngeal carcinoma patients treated with radiotherapy. Oral Surg Oral Med Oral Pathol Oral Radiol Endod 2006;101:332337.

7. Rodrigues NA, Killion L, Hickey G, Silver B, ve ark. A prospective study of salivary gland function in lymphoma patients receiving head and neck irradiation. Int J Radiat Oncol Biol Phys. 2009 Nov 15;75(4):1079-83.

8. Hey J, Setz J, Gerlach R, Vordermark D, ve ark. Effect of Cisplatin on parotid gland function in concomitant radiochemotherapy. Int J Radiat Oncol Biol Phys. 2009 Dec 1;75(5):1475-80.

9. Ricchetti F, Wu B, McNutt T, Wong J, ve ark. Volumetric change of selected organs at risk during IMRT for oropharyngeal cancer. Int J Radiat Oncol Biol Phys. 2011 May 1;80(1):161-8.

10. Teshima K, Murakami R, Tomitaka E, Nomura T, ve ark. Radiation-induced parotid gland changes in oral cancer patients: correlation between parotid volume and saliva production. Jpn J Clin Oncol. 2010 Jan;40(1):42-6.

11. Broggi S, Fiorino C, Dell'Oca I, Dinapoli N, ve ark. A twovariable linear model of parotid shrinkage during IMRT for head and neck cancer. Radiother Oncol. 2010 Feb;94(2):206-12.

12. Deasy JO, Moiseenko V, Marks L, Chao KS, ve ark. Radiotherapy dose-volume effects on salivary gland function. Int J Radiat Oncol Biol Phys. 2010 Mar 1;76(3 Suppl):S58-63.

13. Dijkema T, Raaijmakers CP, Ten Haken RK, Roesink JM, ve ark. Parotid gland function after radiotherapy: the combined michigan and utrecht experience. Int J Radiat Oncol Biol Phys. 2010 Oct 1;78(2):449-53.

14. Dirix P, De Keyzer F, Vandecaveye V, Stroobants S, ve ark. Diffusion-weighted magnetic resonance imaging to evaluate major salivary gland function before and after radiotherapy. Int J Radiat Oncol Biol Phys. 2008 Aug 1;71(5)1:1365-71.

15. Marzi S, Iaccarino G, Pasciuti K, Soriani A, ve ark. Analysis of salivary flow and dose-volume modeling of complication incidence in patients with head-and-neck cancer receiving intensity-modulated radiotherapy. Int $\mathbf{J}$ Radiat Oncol Biol Phys. 2009 Mar 15;73(4):1252-9. 